\title{
COMMENTARY
}

\section{Should we use early less invasive hemodynamic monitoring in unstable ICU patients?}

\author{
Maurizio Cecconi ${ }^{1}$ and David Bennett ${ }^{* 2}$ \\ See related research by Takala et al., http://ccforum.com/content/15/3/R148
}

\begin{abstract}
In the previous issue of Critical Care, Takala and colleagues presented the results of a multicenter study to investigate whether the early presence of less invasive hemodynamic monitoring improves outcome in patients admitted with hemodynamic instability to the intensive care unit. The authors' results suggest that it makes no difference. We discuss these findings and compare them to the literature on early goal-directed therapy in which monitors are used early but with a protocol.
\end{abstract}

In the previous issue of Critical Care, Takala and colleagues [1] published a multicenter randomized controlled trial (RCT) investigating the use of less invasive cardiac output monitoring in hemodynamically unstable patients admitted to the intensive care unit (ICU). In this study, patients were randomly assigned to be treated with (MICO group) or without (control group) a minimally invasive cardiac output monitor based on pulse pressure analysis (FloTrac Vigileo, version 1.07; Edwards Lifesciences, Irvine, CA, USA).

The hypothesis of the study was that if clinicians were given extra information on cardiac output they would be able to manage hemodynamic instability in a more effective way. The primary outcome of the investigation was the achievement of hemodynamic stability within 6 hours of entering the study. ICU mortality and hospital mortality were considered secondary outcomes. There were no differences in any of these outcomes between the control and protocol groups.

The conclusion from these results is that early monitoring of cardiac output in patients admitted with hemodynamic instability to the ICU is not associated with an improved

\footnotetext{
*Correspondence: ebennett4@mac.com

${ }^{2}$ General Intensive Care, Guy's and St Thomas' Hospital, Westminster Bridge Road, London, SE1 7EH, UK

Full list of author information is available at the end of the article
}

outcome. There may be several explanations for this. The literature on the use of hemodynamic monitoring in improving the outcome of either septic or surgical patients provides two constant features: the use of treatment protocols with specific hemodynamic targets and very early application of these protocols. The use of such hemodynamic monitoring is often referred to as early goal-directed therapy (EGDT).

In this study, there was no protocolized treatment. There were qualitative guidelines instead of specific hemodynamic targets. The authors acknowledge that this is one of the limitations of the study and that it may explain the lack of a positive result. Interestingly, this lack of outcome benefit when hemodynamic monitoring is used without a protocol is consistent with data in the literature. RCTs in which pulmonary artery catheters (PACs) have been used without a protocol have not shown any outcome benefit $[2,3]$. In contrast, when the PAC has been coupled with an EGDT approach, there have been improved outcomes [4-8]. Importantly, the targets and the intervention in the protocol need to be very specific while the use of guidelines is not associated with an improved outcome [9]. However, there are RCTs in which the use of PACs coupled with treatment protocols has not shown any outcome benefit $[10,11]$. In these studies, the protocols were not applied 'early' and patients were enrolled even if organ failure had developed [12]. It is clear, therefore, that timing of entry into a protocol is fundamental to its success or failure.

The present study was started promptly: in the MICO group, arterial pressure monitoring was achieved 20 minutes after admission to the ICU and entry into the study occurred less than 1 hour later. It is highly unlikely that this period could be significantly shortened. It is probably significant that the median time from hospital to ICU admission is 13 hours and has a very substantial range. It may be, therefore, that the patients were already too sick to benefit from any hemodynamic intervention. In septic patients, goal-directed therapy started in the emergency department [13] has demonstrated great benefits in survival whereas it makes no difference in survival if applied late $[10,11]$. 
Takala and colleagues [1] used a Vigileo (version 1.07). This monitor was used successfully in two recently published trials: one by Benes and colleagues [14] with Vigileo version 1.10 and one by Cecconi and colleagues [15] with version 1.07. It is important to note that, in these two studies, the monitor was used in a different population (elective surgical patients). It may be that the monitor provides more accurate information in relatively stable, elective surgery patients, in contrast to the heterogeneous hemodynamically unstable population of patients in the present study, in which the data provided by the monitor may be less accurate.

We concur with the authors that the main limitation of this study is the lack of a protocol in the MICO group. No study in the literature demonstrates a benefit from the use of hemodynamic monitoring in the absence of a protocol, a finding that this study seems to confirm.

The authors must be congratulated for studying the use of less invasive hemodynamic monitoring in such a challenging population. The role of EGDT in hemodynamically unstable patients in the ICU is, therefore, still unproven. A study that proves this role would be a major contribution to the management of critically ill, unstable patients.

\section{Abbreviations}

EGDT, early goal-directed therapy; ICU, intensive care unit; MICO, minimally invasive cardiac output monitor; PAC, pulmonary artery catheter; RCT, randomized controlled trial.

\section{Competing interests}

$M C$ has received honoraria, travel expenses, or research support from LiDCO Ltd (Cambridge, UK), Edwards Lifesciences LLC (Irvine, CA, USA), Cheetah Medical, Inc. (Vancouver, WA, USA), Masimo Corporation (Irvine, CA, USA), and Bmeye (Amsterdam, The Netherlands). DB has received honoraria and travel expenses from LiDCO Ltd and Deltex Medical (Chichester, UK).

\section{Author details}

'General Intensive Care, St George's Hospital, Blackshaw Road, London, SW17 0QT, UK. ' General Intensive Care, Guy's and St Thomas' Hospital, Westminster Bridge Road, London, SE1 7EH, UK.

Published: 29 July 2011

\section{References}

1. Takala J, Ruokonen E, Tenhunen JJ, Parviainen I, Jakob SM: Early non-invasive cardiac output monitoring in hemodynamically unstable intensive care patients: a multi-center randomized controlled trial. Crit Care 2011, 15:R148.
2. Rhodes A, Cusack RJ, Newman PJ, Grounds RM, Bennett ED: A randomised controlled trial of the pulmonary artery catheter in critically ill patients. Intensive Care Med 2002, 28:256-264.

3. Harvey SE, Welch CA, Harrison DA, Rowan KM, Singer M: Post hoc insights from PACMan--the U.K. pulmonary artery catheter trial. Crit Care Med 2008, 36:1714-1721.

4. Lobo SM, Salgado PF, Castillo VG, Borim AA, Polachini CA, Palchetti JC, Brienzi SL, deOliveira GG: Effects of maximizing oxygen delivery on morbidity and mortality in high-risk surgical patients. Crit Care Med 2000, 28:3396-3404.

5. Pölönen P, Ruokonen E, Hippeläinen M, Pöyhönen M, Takala J: A prospective, randomized study of goal-oriented hemodynamic therapy in cardiac surgical patients. Anesth Analg 2000, 90:1052-1059.

6. Shoemaker WC, Appel PL, Kram HB, Waxman K, Lee TS: Prospective trial of supranormal values of survivors as therapeutic goals in high-risk surgical patients. Chest 1988, 94:1176-1186.

7. Boyd O, Grounds RM, Bennett ED: A randomized clinical trial of the effect of deliberate perioperative increase of oxygen delivery on mortality in highrisk surgical patients. JAMA 1993, 270:2699-2707.

8. Wilson J, Woods I, Fawcett J, Whall R, Dibb W, Morris C, McManus E: Reducing the risk of major elective surgery: randomised controlled trial of preoperative optimisation of oxygen delivery. BMJ 1999, 318:1099-1103.

9. Sandham JD, Hull RD, Brant RF, Knox L, Pineo GF, Doig CJ, Laporta DP, Viner S, Passerini L, Devitt H, Kirby A, Jacka M; Canadian Critical Care Clinical Trials Group: A randomized, controlled trial of the use of pulmonary artery catheters in high-risk surgical patients. N Engl J Med 2003, 348:5-14.

10. Gattinoni L, Brazzi L, Pelosi P, Latini R, Tognoni G, Pesenti A, Fumagalli R: A trial of goal-oriented hemodynamic therapy in critically ill patients. SvO2 Collaborative Group. N Engl J Med 1995, 333:1025-1032.

11. Hayes MA, Timmins AC, Yau EH, Palazzo M, Watson D, Hinds CJ: Oxygen transport patterns in patients with sepsis syndrome or septic shock: influence of treatment and relationship to outcome. Crit Care Med 1997, 25:926-936.

12. Kern JW, Shoemaker WC: Meta-analysis of hemodynamic optimization in high-risk patients. Crit Care Med 2002, 30:1686-1692.

13. Rivers E, Nguyen B, Havstad S, Ressler J, Muzzin A, Knoblich B, Peterson E, Tomlanovich M: Early goal-directed therapy in the treatment of severe sepsis and septic shock. N Engl J Med 2001, 345:1368-1377.

14. Benes J, Chytra I, Altmann P, Hluchy M, Kasal E, Svitak R, Pradl R, Stepan M: Intraoperative fluid optimization using stroke volume variation in high risk surgical patients: results of prospective randomized study. Crit Care 2010, 14:R118

15. Cecconi M, Fasano N, Langiano N, Divella M, Costa MG, Rhodes A, Della Rocca G: Goal Directed Haemodynamic Therapy during elective total hip arthroplasty under regional anaesthesia. Crit Care 2011, 15:R132.

doi:10.1186/cc10287

Cite this article as: Cecconi M, Bennett D: Should we use early less invasive hemodynamic monitoring in unstable ICU patients? Critical Care 2011, 15:173. 